\title{
RETOS Y PROBLEMAS EN EL DIAGNÓSTICO MICROBIOLÓGICO EN DIARREA
}

\author{
Alfredo Guillén ${ }^{1,2}$, Johnny Lucho ${ }^{3, b}$
}

\begin{abstract}
RESUMEN
Los laboratorios de Microbiología Clínica en el Perú cumplen con la labor de diagnosticar los agentes infecciosos presentes en las muestras clínicas, para lo cual cuentan con diferentes herramientas; su utilización depende de contar con recursos materiales y humanos. El laboratorio microbiológico puede realizar pruebas simples como complejas dependiendo del nivel en que se encuentra, la ubicación geográfica y los recursos disponibles. Se mencionan los problemas encontrados con los procedimientos de laboratorio disponibles y su potencial en la ayuda diagnóstica. Se hace hincapié en contar con procedimientos estandarizados, formación y capacitación continua del personal, así como la importancia de la red de laboratorios liderada por el Instituto Nacional de Salud.
\end{abstract}

\section{CHALLENGES AND PROBLEMS IN THE MICROBIOLOGICAL DIAGNOSIS IN DIARRHEA}

\begin{abstract}
Clinical microbiology laboratories in Peru have the task to diagnose the infectious agents present in the clinical samples, for this, they have different tools available; their use depends on having material and human resources. The microbiological laboratory can perform simple and complex tests, depending on the level, the geographical location and the available resources. We mention the problems found with the available laboratory procedures and their potential diagnostic aid. We emphasize the need of having standardised procedures, the continuous education and training of the staff, and the importance of the laboratory network led by the Instituto Nacional de Salud.
\end{abstract}

Los laboratorios de microbiología clínica cumplen con la labor de diagnosticar los agentes infecciosos presentes en las muestras clínicas, sin embargo, su labor transcurre entre vaivenes de capacidad de recursos materiales y humanos. Esto se puede apreciar desde actividades relativamente sencillas como la microscopía hasta las más complejas como la identificación bacteriana de microorganismos exigentes y la susceptibilidad antimicrobiana.

El médico, frente a un paciente que acude por presentar un cuadro diarreico, debe decidir cuál es la posible etiología y qué tipo de tratamiento debe dar, por lo que recurre al laboratorio a fin de obtener un diagnóstico microbiológico que permita realizar un abordaje racional de la enfermedad. Se conoce que la mayoría de los cuadros diarreicos son autolimitados y que, si bien en algunos casos la etiología es microbiana, en muchos otros pueden deberse a una toxina química, un cuadro alérgico o algún alimento irritante como el alcohol. Lamentablemente, existe un abuso en el uso de antibióticos, a pesar de que la causa más común de cuadros diarreicos no es necesariamente bacteriana, lo cual puede conducir a problemas como el aumento de la resistencia bacteriana y a situaciones tan peligrosas como el desarrollo de colitis pseudomembranosa.

Un interrogatorio y examen físico apropiados, aunados al examen de las heces pueden ayudar al médico a decidir si se trata de una diarrea secretoria, donde hay gran pérdida de líquido y lo que necesita el paciente es hidratación; o una diarrea inflamatoria donde hay invasión de la mucosa por bacterias como Shigella flexneri o Campylobacter, y las heces presentan moco, sangre o ambos, casos en los cuales sí es necesario el uso de antibióticos (Figura 1).

El laboratorio microbiológico apoya al médico en esta decisión, realizando pruebas simples como un examen de reacción inflamatoria en heces, y procedimientos más complejos como cultivos, pruebas rápidas, enzimoinmunoanálisis (ELISA) o pruebas

\footnotetext{
Facultad de Tecnología Médica, Universidad Nacional Federico Villarreal.

Laboratorio de Microbiología, Clínica San Borja.

3 Centro Nacional de Salud Pública, Instituto Nacional de Salud, Lima Perú.

a Médico Microbiólogo; b Tecnólogo Médico.
}

Recibido: 01-02-11 Aprobado: 09-03-11 

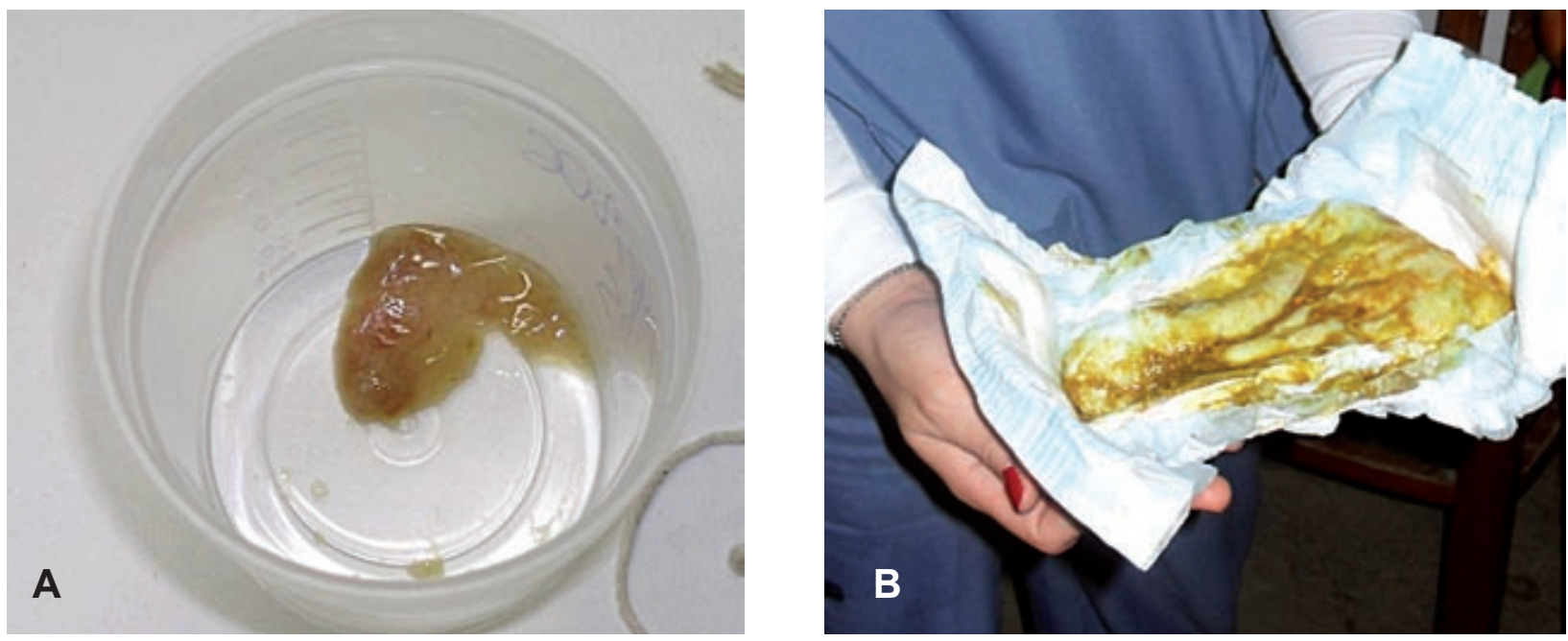

Figura 1. A. Heces compuestas por moco y rasgos de sangre características de un cuadro disentérico en el cual se aisló Shigella flexneri. B. Heces líquidas con presencia de moco y sangre en un paciente menor de 1 año (cortesía Sonia Guillén B., UPC).

moleculares. Pero si observamos lo que sucede en muchos laboratorios, encontraremos que no existe una metodología uniforme, ni se dispone de todos los procedimientos necesarios para obtener información tanto de importancia clínica como epidemiológica.

Entre los métodos para la investigación etiológica de las enfermedades diarreicas tenemos:

Métodos moleculares: existen métodos moleculares como la reacción en cadena de la polimerasa (PCR) para determinar la presencia de algunos agentes microbianos y virales causantes de diarrea así como sus factores de virulencia ${ }^{(1,2)}$. Las ventajas de estas pruebas son su alta sensibilidad y especificidad; inclusive, se ha encontrado que los factores de virulencia presentes en Escherichia coli enteropatógenas pueden ser determinados con gran exactitud por PCR, dejando obsoletos a procedimientos como la serotipia ${ }^{(3-4)}$. Además, los métodos moleculares tienen la ventaja de ser rápidos ${ }^{(5-6)}$. Como desventajas tenemos que el PCR no puede diferenciar bacterias vivas de bacterias muertas que podrían haber sido ingeridas con los alimentos, su elevado costo y la gran demanda de trabajo para su procesamiento. En otro aspecto, los métodos moleculares no proveen de una cepa que pueda ser utilizada para la identificación final, el biotipaje u otros procedimientos microbiológicos. Esto hace que en este momento en el Perú estas pruebas solo estén disponibles en laboratorios universitarios o de investigación. Como contribución adicional, actualmente los laboratorios de referencia están utilizando la electroforesis de campo pulsado para la subtipificación de enteropatógenos permitiendo la identificación de brotes asociados con alimentos ${ }^{(7-8)}$.
Métodos microbiológicos: los laboratorios clínicos en hospitales, clínicas y laboratorios en el Perú, al no poder contar con pruebas moleculares ofrecen realizar cultivos y otras pruebas rápidas para identificar los agentes más prevalentes en nuestro medio. Lo ideal sería hacer un coprocultivo que tenga todos los medios para realizar el aislamiento de Shigella, Salmonella, Campylobacter, E. coli enteropatógena (EPEC, EIEC y EHEC), Yersinia, Vibrio y Aeromonas, además de contar con las pruebas bioquímicas, sueros para identificación necesarios y para realizar las pruebas de susceptibilidad; adicionalmente debe contar con pruebas rápidas para la detección de rotavirus y adenovirus. Lo que se espera es que un coprocultivo se realice como se muestra en la Figura 2 , ello permitirá una adecuada vigilancia de los agentes productores de diarrea ${ }^{(9-10)}$.

Otros agentes causantes de diarrea como E. coli enterotoxigénica o Staphylococcus aureus productor de enterotoxina, no cuentan con pruebas de diagnóstico que puedan ser utilizadas en el trabajo diario de un laboratorio clínico y existe una gran demanda en la investigación y desarrollo de pruebas que puedan cubrir esta brecha.

Sin embargo, muchos laboratorios no realizan todos los procedimientos, y de acuerdo con sus posibilidades económicas, implementación o nivel del conocimiento y experiencia del profesional microbiólogo encargado, solo realizan parte del coprocultivo como se ve en la Figura 2. Muchas veces uno observa con inquietud que se hagan grandes esfuerzos para el aislamiento de Salmonella, cuya incidencia actual es baja, y descuida la búsqueda de Campylobacter, que es una bacteria 


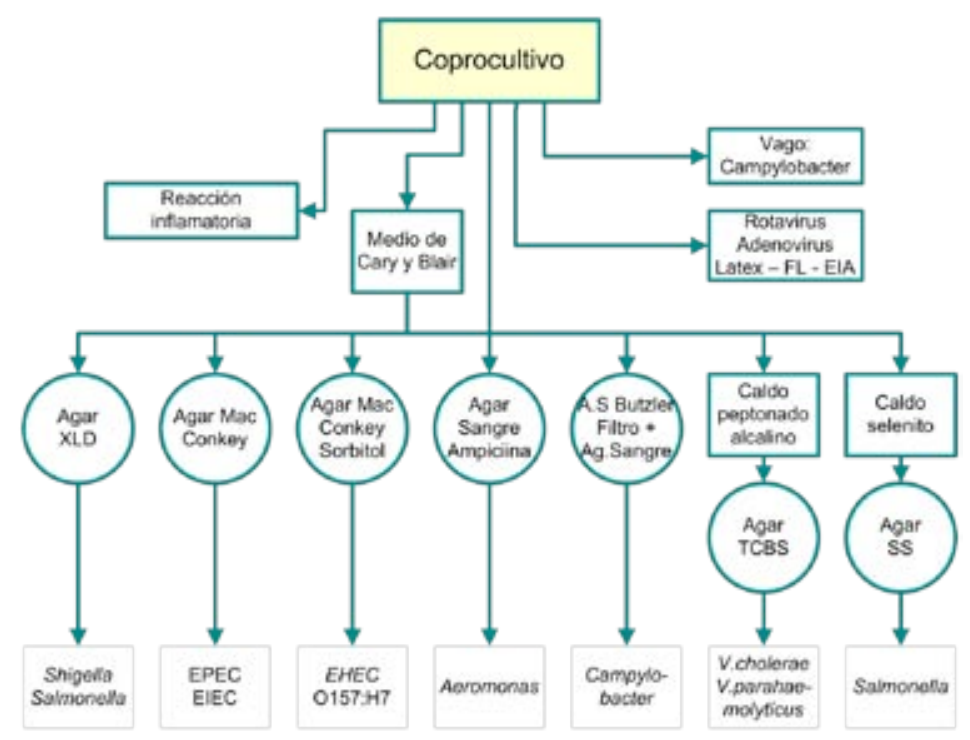

Figura 2. Coprocultivo convencional, todo laboratorio debería tener el material necesario para realizar estos procedimientos como mínimo.

prevalente, sobre todo en niños menores de 6 años. Por otro lado, la búsqueda de Vibrio, ha sido dejada de lado por muchos laboratorios debido a su baja incidencia. Sin embargo, algunos laboratorios clínicos que siguen utilizando el agar TCBS han visto que la incidencia de Vibrio parahaemolyticus es frecuente en los meses de verano y que de presentarse un brote de Vibrio cholerae algunos laboratorios nacionales no tendrían los medios necesarios para su aislamiento e identificación, a pesar de los esfuerzos del Instituto Nacional de Salud que, preocupado por un posible brote, sigue capacitando a los laboratorios y proporcionando sueros para tipificación de Vibrio preparados por el Centro Nacional de Productos Biológicos del INS. Lamentablemente la falta de recursos asignados para la realización de pruebas de laboratorio en muchos centros dependientes del Ministerio de Salud, impide la implementación de las pruebas descritas en su totalidad. Evidentemente, la prevención y detección temprana de brotes epidémicos de diarrea requieren del compromiso de las autoridades correspondientes a fin de asegurar la capacidad de detección tanto en hospitales como en centros periféricos.

Pruebas rápidas: existen pruebas rápidas disponibles para la búsqueda de Campylobacter, Giardia lamblia, toxina A de Clostridium difficile (colitis pseudomembranosa asociada con el uso de antimicrobianos), rotavirus y adenovirus. Existen diferentes procedimientos y se utiliza la aglutinación con partículas de látex, pruebas de flujo lateral (inmunocromatografía) o enzimoinmunoanalisis (ELISA). Las pruebas más utilizadas son para la detección de virus en diarreas que se presentan en niños, especialmente aquellas asociadas con rotavirus ${ }^{(11)}$. Las pruebas rápidas tienen un costo moderado que puede ser limitante en algunos establecimientos de salud o para algunos grupos poblacionales, pero la información clínica y epidemiológica que puedan proveer es importante. Para Campylobacter y Giardia existen métodos más económicos, como la coloración de Vago y el examen directo.

Medios cromogénicos: estos medios se están utilizando cada vez más en los laboratorios de microbiología y, en el caso de diarreas, se han utilizado para el aislamiento e identificación de Vibrio cholerae, $V$. parahaemolyticus y E. coli O157. El desarrollo característico de un color facilita la identificación en forma rápida y específica de los agentes infecciosos; sin embargo, el costo es una limitante para el uso generalizado de estos medios.

Los laboratorios de microbiología clínica deben contar con personal capacitado, principalmente tecnólogos médicos y médicos patólogos clínicos, que tengan un entrenamiento específico en el diagnóstico microbiológico. A diferencia de otras áreas del laboratorio (bioquímica, hematología) en las cuales se tiende a la automatización, esta es muy restringida en microbiología (por ejemplo en el caso de hemocultivos, identificación y pruebas de susceptibilidad), por lo que la competencia del personal resulta ser particularmente relevante.

Como se expuso previamente, los laboratorios de microbiología clínica suelen contar con personal capacitado para el diagnóstico de enfermedades diarreicas, siendo la limitante habitual en el diagnóstico, el no contar con medios de cultivo, reactivos, sueros para la identificación de los agentes más frecuentes, entre otras deficiencias. 


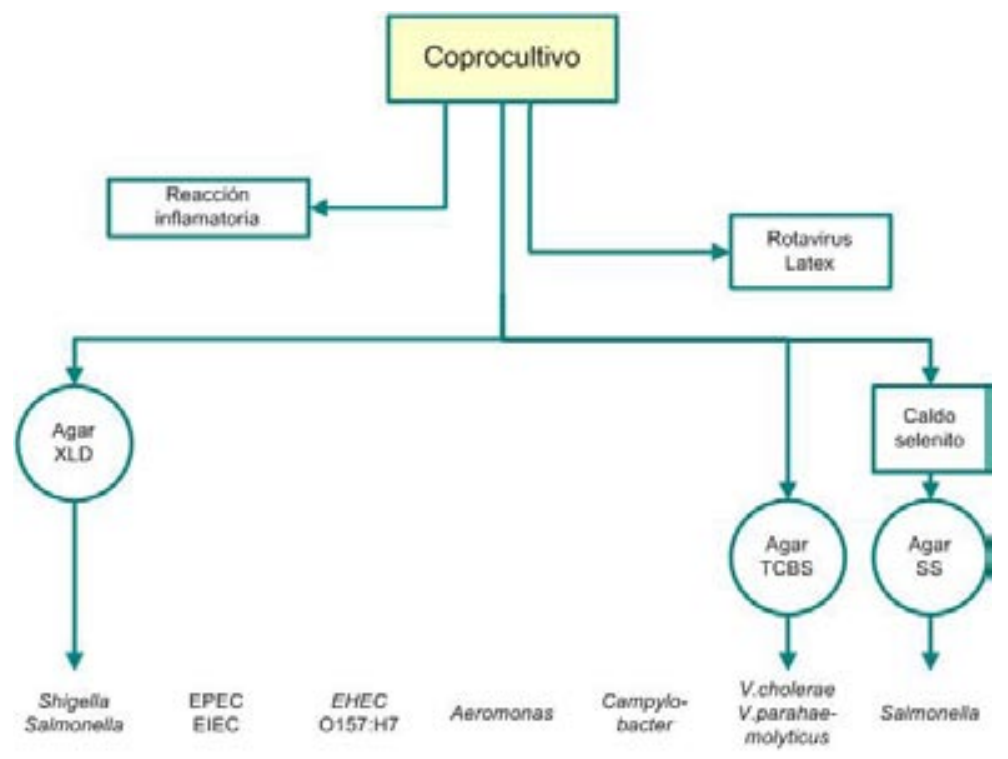

Figura 3. Coprocultivo "acortado".

En concordancia, es necesario contar con:

1. Procedimientos estandarizados bajo una norma técnica nacional para que los laboratorios puedan exigir la implementación adecuada de los laboratorios con los medios y reactivos necesarios.

2. Formación en pregrado y capacitación continua del personal, a cargo de los laboratorios de referencia regional y nacional e instituciones educativas (universidades). La educación a distancia, utilizando Internet, videoconferencias, correo electrónico e incluso redes sociales son modalidades de enseñanza y aprendizaje en los cuales el personal ya no necesita estar físicamente en un laboratorio para poder aprender.

A pesar de las limitaciones expuestas, la red de laboratorios es una realidad en estos momentos y el esfuerzo del Instituto Nacional de Salud en crear, capacitar e implementar los laboratorios ha dado fruto, cuyos éxitos se han visto durante la presencia de brotes epidémicos y enfermedades relacionadas como el cólera y la tifoidea. Este esfuerzo debe ser complementado por los decisores locales con la implementación de los laboratorios regionales y locales fin de lograr optimizar el diagnóstico de una condición de tanta importancia en salud pública como lo es la enfermedad diarreica.

En conclusión, el diagnostico etiológico de las infecciones diarreicas en el Perú, es factible en la mayoría de casos por la variedad de métodos existentes, así como por la capacidad del personal. Sin embargo, muchos laboratorios microbiológicos no tienen la capacidad logística de insumos y reactivos para poder utilizar estos métodos. La capacitación del personal de la red de laboratorios, tal como la viene desarrollando el Instituto Nacional de Salud, es primordial para el aseguramiento de la calidad de los procedimientos; a este esfuerzo deben sumarse los laboratorios de referencia e instituciones educativas. Finalmente, Se requiere tener instrumentos normativos o guías que sirvan de parámetros para la implementación adecuada de los laboratorios.

\section{Fuentes de Financiamiento}

Autofinanciado.

\section{Conflictos de Interés}

Los autores declaran no tener conflictos de interés en la publicación del presente artículo.

\section{REFERENCIAS BIBLIOGRÁFICAS}

1. De Boer RF, Ott A, Kesztyüs B, Kooistra-Smid AM. Improved detection of five major gastrointestinal pathogens by use of a molecular screening approach. J Clin Microbiol. 2010, 48: 4140-4146.

2. Huguet J, Arias I, Montoya Y. Tipificación molecular de Vibrio cholerae 01 en el Perú. Rev Peru Med Exp Salud Publica. 2000, 17: 9-13.

3. Ochoa TJ, Mercado EH, Durand D, Rivera FP, Mosquito S, Contreras C, et al. Escherichia coli diarrogénica en niños peruanos. Rev Peru Med Exp Salud Publica. 2011; 28 (1) [En prensa].

4. Riveros M, Barletta F, Cabello M., Durand D, Mercado $\mathrm{EH}$, Contreras C, et al. Patrones de adherencia de 
cepas de Escherichia coli difusamente adherente (DAEC) provenientes de niños con y sin diarrea. Rev Peru Med Exp Salud Publica. 2011; 28 (1) [En prensa].

5. Cunningham SA, Sloan LM, Nyre LM, Vetter EA, Mandrekar J, Patel R. Three-hour molecular detection of Campylobacter, Salmonella, Yersinia, and Shigella species in feces with accuracy as high as that of culture. J Clin Microbiol. 2010; 48:2929-2933.

6. Kulkarni SP, Lever S, Logan JM, Lawson AJ, Stanley J, Shafi MS. Detection of Campylobacter species: a comparison of culture and polymerase chain reaction based methods. J Clin Pathol. 2002; 55:749-753.

7. Boxrud D, Monson T, Stiles T, Besser J. The role, challenges, and support of pulsenet laboratories in detecting foodborne disease outbreaks. Public Health Rep. 2010;125 Suppl 2:57-62.

8. Halpin JL, Garrett NM, Ribot EM, Graves LM, Cooper KL. Re-evaluation, optimization, and multilaboratory validation of the PulseNet-standardized pulsed-field gel electrophoresis protocol for Listeria monocytogenes. Foodborne Pathog Dis. 2010; 7:293-298.
9. Huapaya B, Huguet J, Suarez M, Torres Y, Montoya Y, Salazar E, et al. Primer aislamiento de Escherichia coli 0157:H7 enterohemorrágica en el Perú. Rev Peru Med Exp Salud Publica. 2001; 18:38-39.

10. Perales M, Camiña M, Quiñones C. Infección por Campylobacter y Shigella como causa de diarrea aguda acuosa en niños menores de dos años en el distrito de La Victoria, Lima - Perú. Rev Peru Med Exp Salud Publica. 2002; 19:186-192.

11. Ayón J, Castro M, Yshi C, Lecca L, Cano C. Enfermedad diarreica aguda por rotavirus en adultos de un establecimiento de salud privado de Lima - Perú. Rev Peru Med Exp Salud Publica. 2004; 21: 183-185.

Correspondencia: Alfredo Guillén.

Dirección: Sor Edecia 130, San Miguel, Lima, Perú.

Correo electrónico: alfredo_guillen@yahoo.com

\section{Consulte la versión electrónica de la} Revista Peruana de Medicina Experimental y Salud Pública en

\section{wWW.scopus.com}

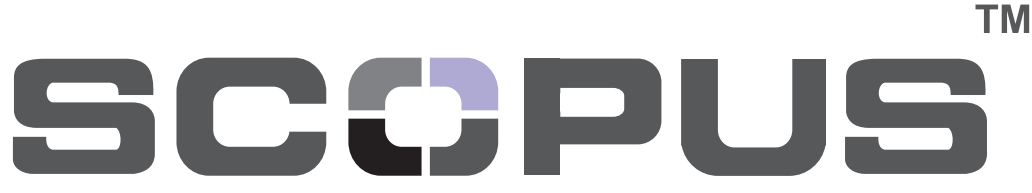

